\title{
Fabrication of biocompatible and mechanically reinforced graphene oxide-chitosan nanocomposite films
}

\author{
Ping-Ping Zuo ${ }^{\dagger}$, Hua-Feng Feng ${ }^{\dagger}$, Zhi-Zhen Xu, Ling-Fan Zhang, Yu-Long Zhang, Wei Xia ${ }^{*}$ and Wen-Qing Zhang ${ }^{*}$
}

\begin{abstract}
Background: Graphene oxide (GO)can be dispersed through functionalization, or chemically converted to make different graphene-based nanocomposites with excellent mechanical and thermal properties. Chitosan, a partially deacetylated derivative of chitin, is extensively used for food packaging, biosensors, water treatment, and drug delivery. GO can be evenly dispersed in chitosan matrix through the formation of amide linkages between them, which is different from previous reports focusing on preparing $\mathrm{GO} /$ chitosan nanocomposites through physical mixing.
\end{abstract}

Results: In this study, free-standing graphene oxide-chitosan (GO-chitosan) nanocomposite films have been prepared. The GO-chitosan films are biologically compatible and mechanically reinforced. Through the formation of amide linkages between GO's carboxylic acid groups and chitosan's amine groups, GO could be evenly dispersed within the chitosan matrix. We also characterized the GO-chitosan composite films using element analysis, Fourier transform infrared spectroscopy, X-ray photo electron spectroscopy, differential scanning calorimetry, and thermo gravimetric analysis. Compared to pristine chitosan film, the tensile strength of GO-chitosan film is improved by 2.5 folds and Young's modulus increases by nearly 4.6 folds. The glass transition temperature of GO-chitosan composite film shifts from $118^{\circ} \mathrm{C}$ to $158^{\circ} \mathrm{C}$ compared to the pristine chitosan, indicating its enhanced thermal stability. GOchitosan composite film was also evaluated for its biocompatibility with C3H10T1/2 cells by in vitro fluorescent staining. The graphene oxide-reinforced chitosan composite films could have applications in functional biomaterials.

Conclusion: The present study describes a useful and simple method to chemically attach biocompatible chitosan onto graphene oxide. We envision that the GO-chitosan film will open avenues for next-generation graphene applications in the realm of functional biomaterial.

Keywords: Graphene oxide, Chitosan, Chemical modification, Biocompatibility, Biofilms

\section{Background}

Since its discovery, graphene has attracted considerable attention due to its fascinating properties [1-4], as evidenced by a substantial amount of primary literature. Perfect two-dimensional single-layered graphene does not exist naturally, but bulk and solution processable functionalized graphene materials, including graphene oxide (GO) have been successfully prepared [5]. The polar functional groups attached on the basal planes and at the edges of GO sheets alter their properties

\footnotetext{
* Correspondence: xiawei1999@ecust.edu.cn; zhwqing@ecust.edu.cn ${ }^{\dagger}$ Equal contributors

School of Chemistry and Molecular Engineering, East China University of Science and Technology, 130 Meilong Road, Shanghai 200237, China
}

significantly [6]. Combined, these altered properties provide convenient access for fabrication of graphene-based materials by solution casting, and can form large-scale uniform films on various substrates. Recent studies [6-8] have shown that GO can be dispersed through functionalization, or chemically converted to make different graphene-based nanocomposites with excellent mechanical and thermal properties. Graphene-based sheets have also been tested as possible nanocarriers for delivering drugs [9] and also as functional biomaterials $[10,11]$. Shen et al. reported graphene oxide-based biocomposites through diimide-activated amidation and found that the covalently bonded biomaterials retained their bioactivity [12], while Dai et al. reported non-toxic PEGylatednano- 
graphene oxide could delivery water-insoluble cancer drugs $[13,14]$.

Chitosan, a partially deacetylated derivative of chitin, is a linear polysaccharide consisting of $\beta(1,4)$-linked D-glucosamine residues (deacetylated unit) with a variable number of randomly located $\mathrm{N}$-acetyl-glucosamine groups (acetylated unit) (Figure 1). As one of the most abundant natural biopolymers on earth, it is extensively used for food packaging, biosensors, water treatment, and drug delivery [15]. It has been reported that chitosan-based biomaterials could promote chondrogenesis [16].

Despite its unique physical properties, the mechanical properties of pristine chitosan are not good enough to satisfy a wide range of applications.

Here we demonstrate that GO can be evenly dispersed in chitosan matrix through the formation of amide linkages between them, which is different from previous reports focusing on preparing $\mathrm{GO} /$ chitosan nanocomposites through physical mixing [17-21]. Since the chitosan can provide a biocompatible, transferable, and implantable condition for cell culture [22,23], we also evaluate the viability of cells on GO-chitosan composite film using C3H10T1/2 cells, for potential applications in growth of articular cartilage [24].

\section{Results and discussion}

ElementarVario EL III was used to analyse the mole ratio of chitosan to GO in the GO-chitosan composite. The amount of N-element in chitosan is about 1:1 (N:chito$\mathrm{san}, \mathrm{mol} / \mathrm{mol}$ ). The elemental analysis shows that GOchitosan is composed of $7.83 \mathrm{wt} \%$ of nitrogen, $42.54 \mathrm{wt} \%$ of carbon, $6.61 \mathrm{wt} \%$ of hydrogen and $43.02 \mathrm{wt} \%$ of oxygen. Based on the results, we can calculate the amount of chitosan in GO-chitosan is $90.05 \mathrm{wt} \%$ and the amount of GO is $9.95 \mathrm{wt} \%$. The mass ratio of GO to chitosan is 1:9 in GO-chitosan compound.

To compare the same component in two different films, the amount of GO is $10.0 \%$ weight in the mixture preparation. The GO/chitosan mix solution contains $0.25 \mathrm{wt} \% \mathrm{GO}$ and $2.25 \mathrm{wt} \%$ chitosan, and the mass ratio of GO to chitosan is $1: 9$, too.

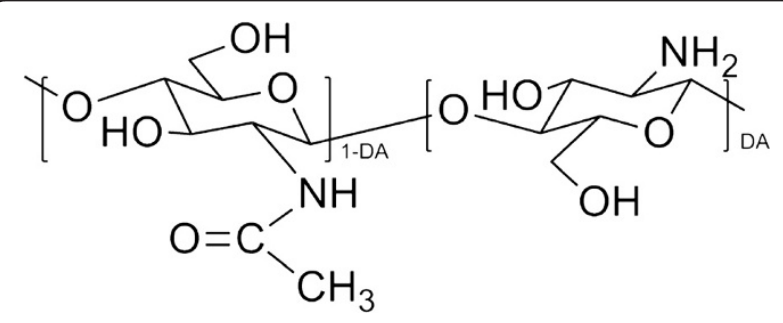

Figure 1 The structure of partially deacetylated chitosan. DA means a copolymer characterized by its average degree of deacetylation.
Fourier transform infrared spectroscopy (FTIR) was used to verify the amide linkage between $\mathrm{GO}$ and chitosan. Spectra of the samples are compared in Figure 2. In the spectrum of GO, we observe dominant peaks are at $1035,1225,1623$ and $1739 \mathrm{~cm}^{-1}$. The peak at $1035 \mathrm{~cm}^{-1}$ corresponds to a stretching vibration from $\mathrm{C}-\mathrm{O}-\mathrm{Cbonds}$ of epoxy or alkoxy. The peak at $1225 \mathrm{~cm}^{-1}$ is attributed to the $\mathrm{C}-\mathrm{OH}$ bonds. While the peak centered at $1623 \mathrm{~cm}^{-1}$ is assigned to $\mathrm{C}=\mathrm{C}$ bonds associated with skeletal vibrations of unoxidized graphite domains. The peak located at $1739 \mathrm{~cm}^{-1}$ is attributed to $\mathrm{C}=\mathrm{O}$ in carboxylic acid and carbonyl moieties [25]. In the spectrum of chitosan, dominant peaks exist at $1029 \mathrm{~cm}^{-1}$ and $1593 \mathrm{~cm}^{-1}$. These peaks correspond to an absorbance of glucosidic bond, stretching vibration from $\mathrm{C}=\mathrm{O}$ of-NHCO-and the N-H bending of $\mathrm{NH}_{2}$, respectively [26]. In the spectra of GO-chitosan, the dominant peaks at $1038 \mathrm{~cm}^{-1}$ and $1594 \mathrm{~cm}^{-1}$ correspond to the absorbance of glucosidic bond, stretching vibration from $\mathrm{C}=\mathrm{O}$ of -NHCO- and the $\mathrm{N}-\mathrm{H}$ bending of $\mathrm{NH}_{2}$, respectively, compared with pure chitosan and GO. In the GOchitosan spectrum and $\mathrm{GO} /$ chitosan mix spectrum, the absence of the peak at $1739 \mathrm{~cm}^{-1}$, corresponding to $\mathrm{C}=\mathrm{O}$ in carboxylic acid and carbonyl moieties in GO,is simply for the mass ratio of GO to chitosan is 1 to 9 in both $\mathrm{GO}$-chitosan and GO/chitosan mix, thus the peak is too weak to be observed.

Following FTIR analysis, we used XPS to further explore the interactions between GO and chitosan. The survey of GO (Figure 3a) shows that no detectable amount of N1s, for the strongest XPS band of N-is usually found between 400 and $407 \mathrm{eV}$ depending on the chemical environment [26]. Figure $3 \mathrm{~b}$ shows the N1s XPS spectra of chitosan, with three different peaks centered at 399.0, 400.5 and $401.6 \mathrm{eV}$. These peaks correspond to $\mathrm{C}-\mathrm{NH}_{2}, \mathrm{C}-\mathrm{NHC}=\mathrm{O}$, and $\mathrm{C}-\mathrm{N}^{+}$, respectively $[27,28]$. Compared with the pristine GO, the survey (Figure 3c) of GO-chitosan shows the presence of N1s originating from chitosan. The N1s spectrum of GOchitosan (Figure 3c) can be convoluted into three peak components with binding energies at 399.4, 400.7, and $401.7 \mathrm{eV}$ [28], attributed to the amine, amide, and the protonated amine species, respectively. Compared with chitosan, the relative increase in amide peak and decrease in protonated amine in GO-chitosan provides the supporting evidence for the formation of new covalent functionalization between the carboxylic acid on the surface of GO and N groups of chitosan. These data are consistent with FTIR. Additionally, we observe a marginal change in the relative heights of peaks 2 and 3 , which indicates few new covalent bonds formed in the GO/chitosanmix (Figure 3d).

Thermal properties of the composite films were evaluated with thermal gravimetric analysis (TGA) and 


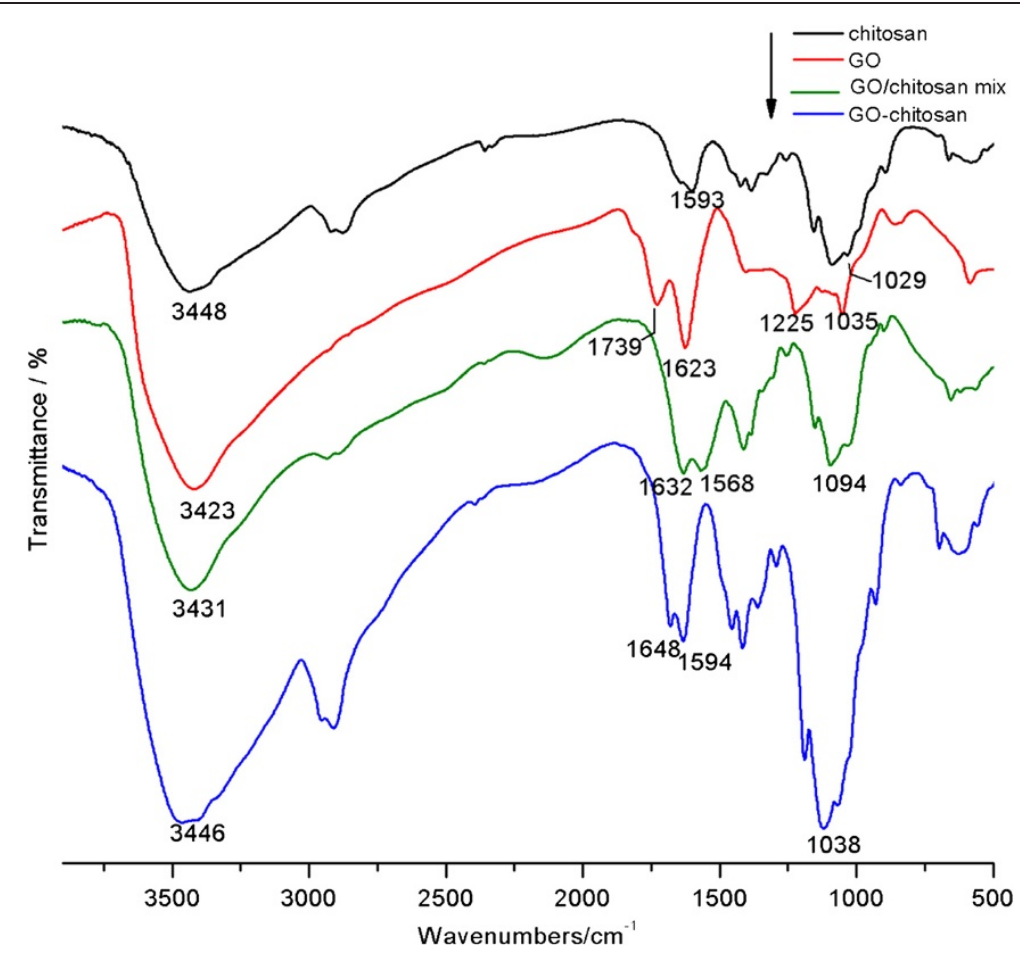

Figure 2 FTIR spectra of chitosan, GO, GO-chitosan and GO/chitosan mix.

differential scanning calorimetry (DSC). TGA reveals the composition and changes in thermal stability of the tested samples. As shown in Figure 4a, GO powder is thermally unstable and starts to lose functional groups below $100^{\circ} \mathrm{C}$, and the major loss occurs at $250^{\circ} \mathrm{C}$, presumably due to pyrolysis of the labile oxygen-containing functional groups, yielding $\mathrm{CO}, \mathrm{CO}_{2}$ and water [29]. Because both GO-chitosan film and $\mathrm{GO} /$ chitosan film are mainly composed of chitosan (GO:chitosan $=1: 9, \mathrm{~m} / \mathrm{m}$ ), their TGA curves are similar to that of the pristine chitosan film and do not have the obviously second major weight loss corresponding to decomposition of GO. Additionally, GO-chitosan is more thermally stable than GO. Apart from a slight mass loss below $150^{\circ} \mathrm{C}$, which can be contributed to loss of water contained in the GO-chitosan film, no significant loss of mass is detected even at $300^{\circ} \mathrm{C}$. The major loss of mass occurs at approximately $300^{\circ} \mathrm{C}$, which is similar to that of chitosan. The chemical modification of thermally labile oxygencontaining functional groups of GO results in significantly increased thermal stability for the GO-chitosan.

The improvement in the thermal stability of the GOchitosan composite can also be evidenced by the glass transition temperatures $(\mathrm{Tg})$ in Figure $4 \mathrm{~b}$. The glass transition occurs at $118-119^{\circ} \mathrm{C}$ for pristine chitosan, whereas it shifts to $132^{\circ} \mathrm{C}$ for $\mathrm{GO} /$ chitosan mixture and $158^{\circ} \mathrm{C}$ for GO-chitosan composites. Both GO-chitosan and $\mathrm{GO} /$ chitosan mix have a rise in the $\mathrm{Tg}$. Since $\mathrm{Tg}$ of polymers is affected by the mobility of polymer chains, the increasing of $\mathrm{Tg}$ and the thermal stability of the composites as compared to pristine chitosan could be inferred that evenly dispersion of GO might effectively hinder the motion of the chitosan chains by electrostatic attraction and hydrogen bonding, as demonstrated in previous reports [30]. Moreover, the chemical linkage between chitosan chains and GO sheets in GO-chitosan composite films might restrict the conformations of polymer molecules in a higher degree than the intermolecular forces, resulting in higher $\mathrm{Tg}$ of GO-chitosan composite films than that of $\mathrm{GO} /$ chitosan mixture.

Figure 5 shows the photographs of the prepared films. To determine the morphology of GO-chitosan film and $\mathrm{GO} /$ chitosan film, we used scanning electron microscopy (SEM). GO-chitosan film in Figure 6a is homogeneous and the fracture-surface image of the film in Figure $6 \mathrm{~b}$ exhibits no stacking of GO. In contrast, the surface of GO/chitosan in Figure $6 \mathrm{c}$ film appears relatively coarse. Some protuberances can be observed in Figure $6 \mathrm{c}$, since GO could aggregate during preparation of composite films. Similar results have been widely observed in the recent studies on polymer-immobilized graphene sheets [31,32]. GO-chitosan film and GO/chitosan film have a "sandwich" structure (Figure $6 \mathrm{~b}$ and $\mathrm{d}$ ). Figure $6 \mathrm{~b}$ demonstrates that most of the GO nanosheets were fully exfoliated and clearly well dispersed in the chitosan matrix. Figure $6 \mathrm{~d}$ shows that GO sheets are 


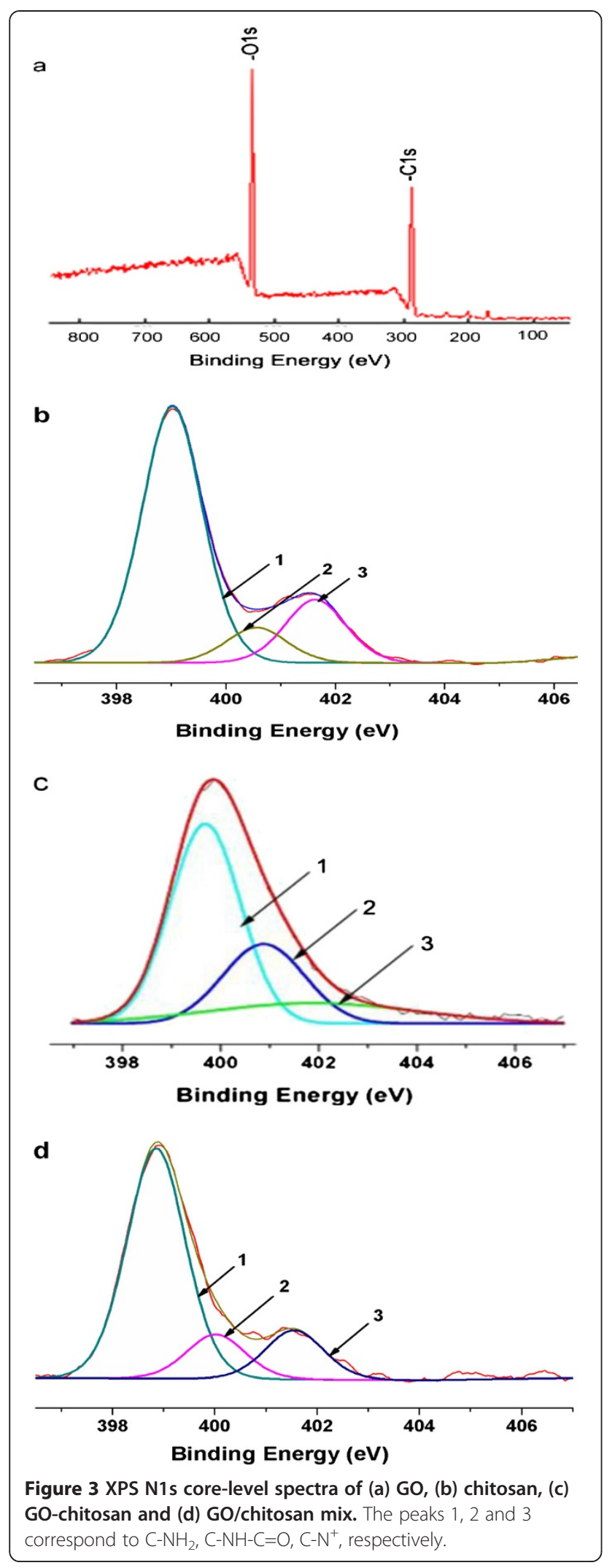

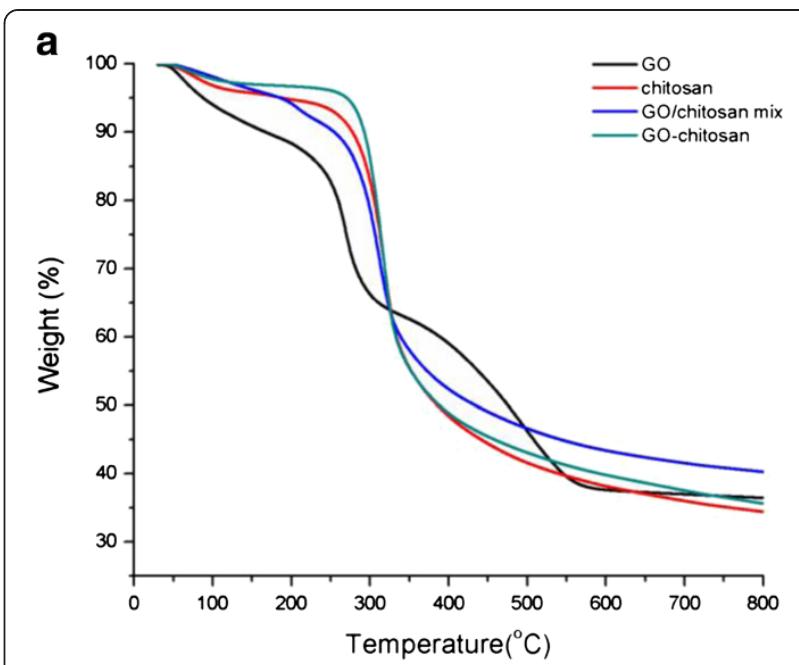

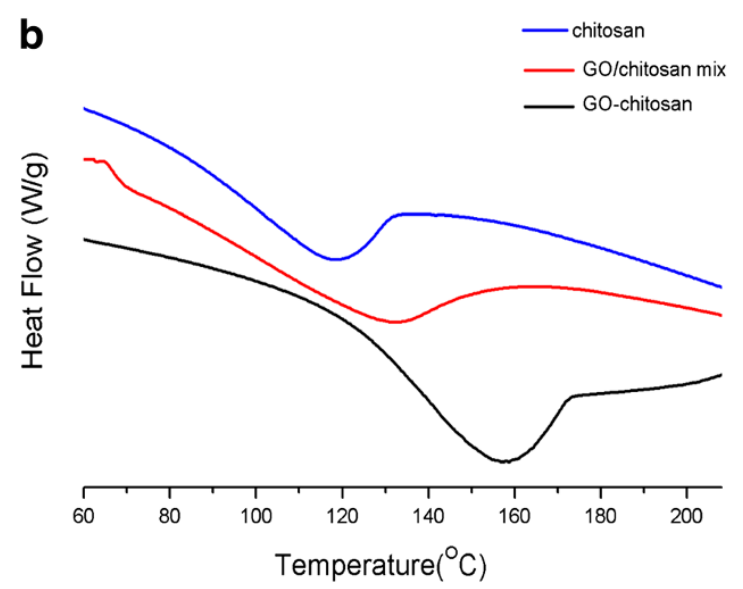

Figure 4 Thermal properties of the composites. a TGA curves ofGO, chitosan, GO/chitosan mix and GO-chitosan. b DSC curves to determine the $\mathrm{Tg}$ of chitosan, GO/chitosan mix and GO-chitosan.

unidirectionally dispersed in the chitosan matrix and parallel to the composite film. Formation of amide linkages between GO and chitosan could facilitate dispersion of GO within the chitosan matrix and thus influence the mechanical properties of the resulting composites, which will be discussed in the following.

The mechanical properties of the pristine chitosan, GO/chitosan and the GO-chitosan films were investigated by mechanical analyser (ZWICK ZO 20/TN2S, Germany) at $20^{\circ} \mathrm{C}$. Mechanical properties of these films are summarized in Table 1, which are in good agreement with their thermal description. GO-chitosan is more thermally stable than $\mathrm{GO} /$ chitosan and GO-chitosan also performances better than $\mathrm{GO} /$ chitosan in mechanical properties. The strong chemical interaction between GO and chitosan and homogeneous dispersion of GOchitosan result in a uniform stress distribution and be able to minimize the occurrence of stress concentration, leading to a significant increase in mechanical properties 


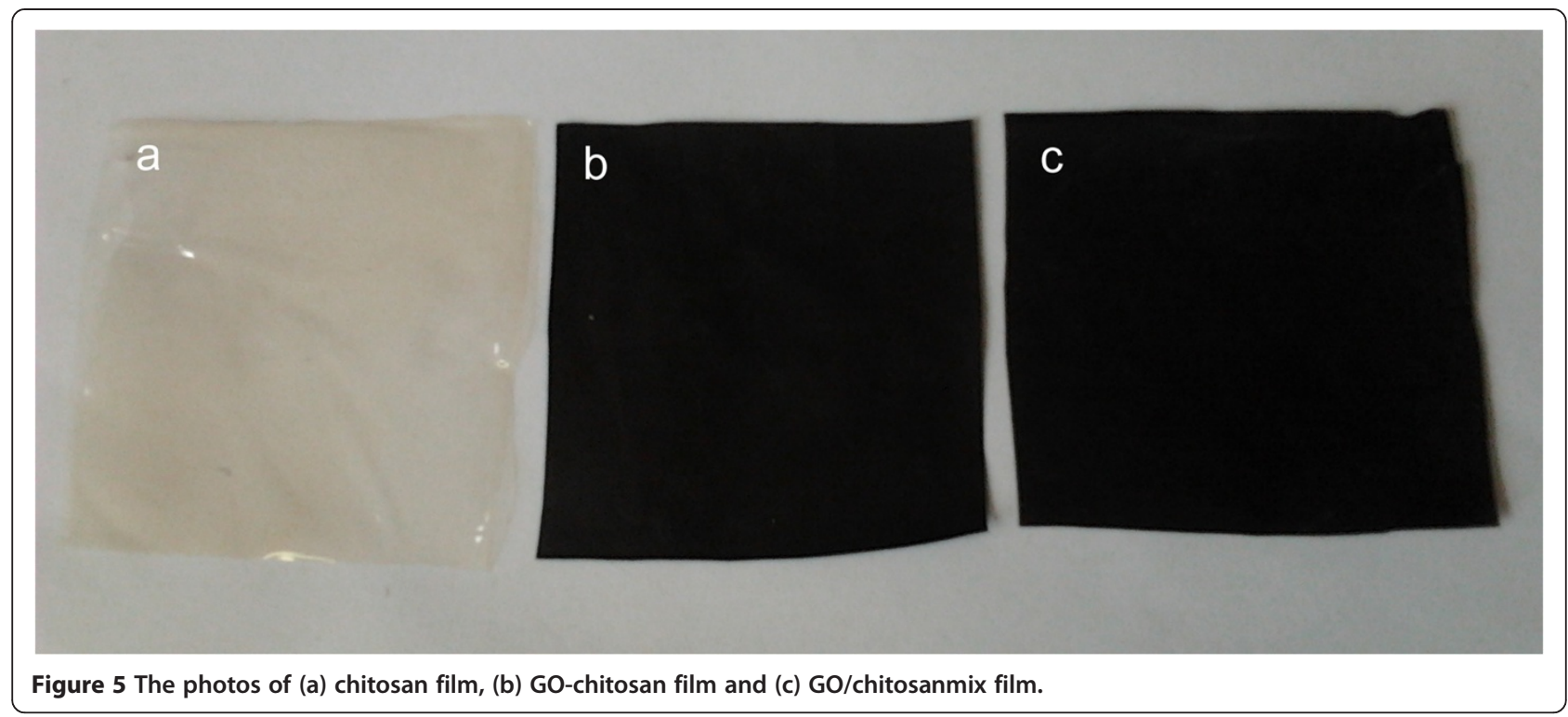

of the resulting nanocomposites. The uniform dispersion, together with the strong interfacial adhesion between GO and chitosan matrix, also enhances the mechanical properties of $\mathrm{GO} /$ chitosan mix film. Although the loading amount of GO in all GO-chitosan films was not very high, it significantly improves the mechanical properties. Figure 7 shows the relationship between the peak load and deformation of the films.
Compared with the pristine chitosan film, the tensile strength of GO-chitosan film increases by 2.5 folds, from 32.7 to $82.0 \mathrm{MPa}$, the tensile strength of $\mathrm{GO} /$ chitosan mix film increases by 1.4 folds, from 32.7 to $43.8 \mathrm{MPa}$. Besides, the addition of $\mathrm{GO}$ reduces the elongation at the break point. This could be attributed to the interaction between $\mathrm{GO}$ and the polymer matrix, which restricts the regular movement of chitosan chains [33].
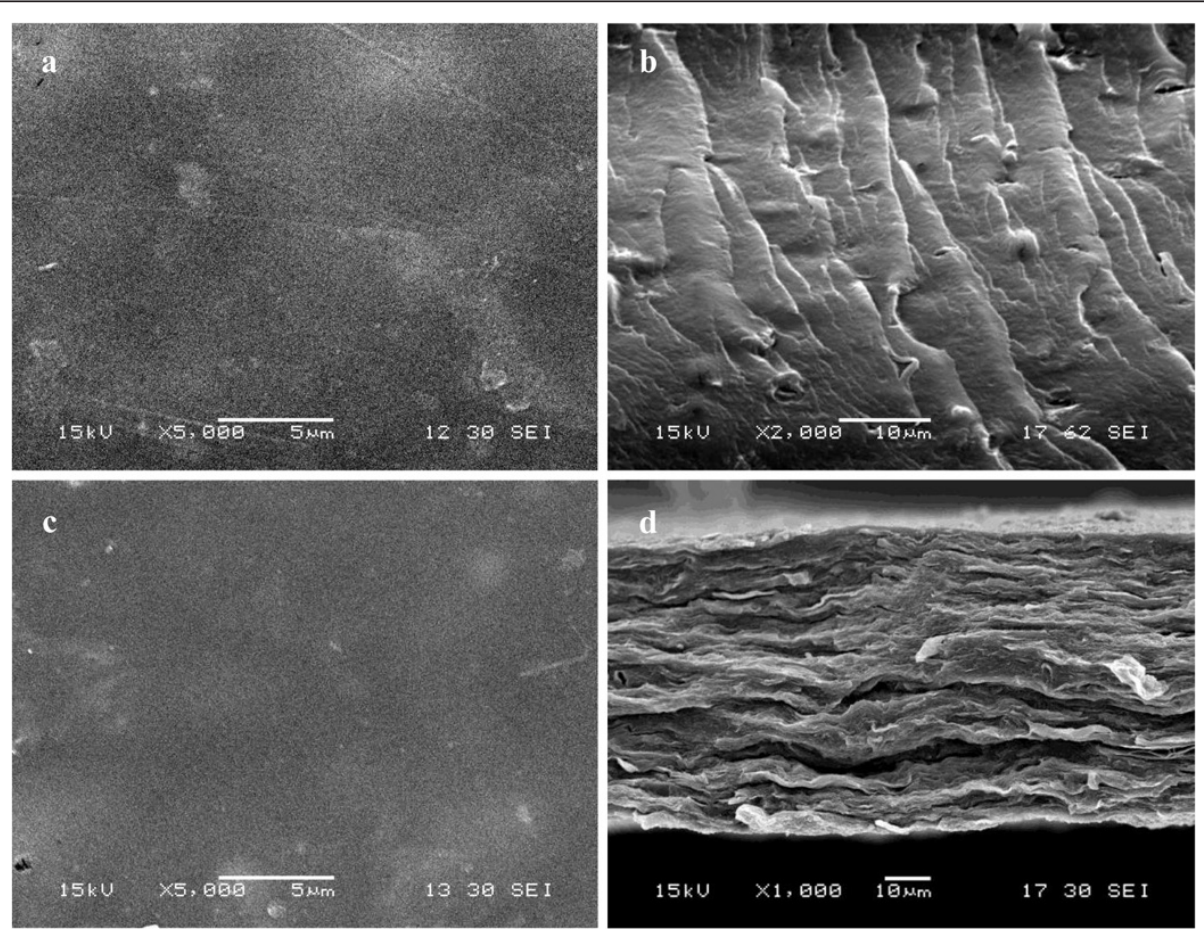

Figure 6 SEM images of GO-chitosan and GO/chitosanmix films, respectively. a. GO-chitosan film-surface image; b. GO-chitosan film fracture-surface image; c. GO/chitosan mix film-surface image; $\mathbf{d}$. GO/chitosan mix film fracture-surface image. 
Table 1 Mechanical properties of films

\begin{tabular}{ccccc}
\hline Film sample & PeakLoad $\mathbf{F}_{\mathbf{b}} / \mathbf{N}$ & Tensile strength $\boldsymbol{\sigma}_{\mathbf{b}} / \mathbf{M P a}$ & Young's modulus E/MPa & Elongation at break $\delta / \%$ \\
\hline chitosan & 9.1 & 32.7 & 447.7 & 71.3 \\
GO/chitosan & 15.2 & 43.8 & 1037.6 & 32.8 \\
GO-chitosan & 24.8 & 82.0 & 2090.5 & 42.5 \\
\hline
\end{tabular}

Therefore, the Young's moduli of GO-chitosan film and $\mathrm{GO} /$ chitosan mix film, as shown in Table 1, nearly increase by 4.6 folds and 2.1 folds than that of pristine chitosan film, respectively. Table 1 also shows that GOchitosan film has a better mechanical performance than GO/chitosan mix film. Some researchers [33] assumed that a few GO restacked due to the van der Waals force and its surface area ratio reduced after certain level of GO loading. Beyond this critical loading limit, further increasing GO content could cause aggregation of GO with the polymer matrix and thus effect the mechanical improvement of chitosan films. So compared with the recent similar studies, we can infer that the GO content in $\mathrm{GO} /$ chitosan mix film may be beyond the critical loading and have less effective enhancement during the tensile testing.

Overall, compared with chitosan film, the increase in thermal and tensile behaviors of GO-chitosan film and GO/chitosan mix film could be ascribed to the loading of GO. On one hand, the reinforcing effect is partly because of the hydrogen bonding between chitosan and $\mathrm{GO}$ at the molecular level [34]. On the other hand, the polycationic nature of chitosan and the anionic nature of GO leads to electrostatic attraction between them also reducing the chain segmental mobility. Besides, GOchitosan film achieves better thermal and tensile properties compared with GO/chitosan mix film. The amide linkage between GO and chitosan in GO-chitosan could contribute to the higher degree of restriction in mobility

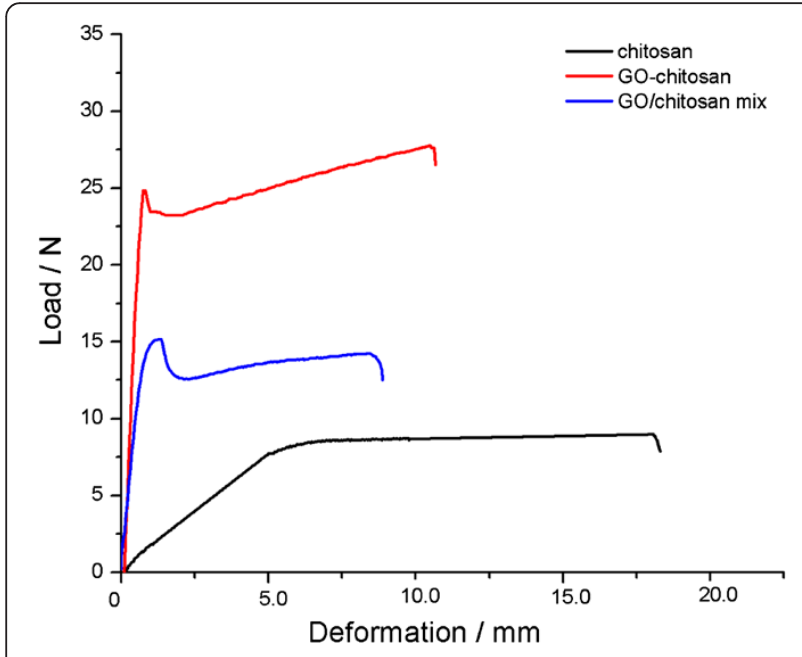

Figure 7 Tensile behaviors of the films. of the chitosan chains and thus lead to the stronger enhanced thermal and tensile properties.

Since chitosan has been widely studied in making biomedical materials, we explore here if the incorporation of GO could influence the biocompatibility of the chitosan with the mouse mesenchymalstem C3H10T1/2. For the quantity of cells adhered to the materials could not be observed by optical microscope due to the poor lightadmitting quality of GO-chitosan films, the results were measured by tracing the nucleus of cells with DAPI. Morphology of cells was shown by double fluorescence staining. DAPI is a fluorescent dye that can penetrate the cell membrane and integrate tightly with DNA. Thus, it is used to fluorescently stain the nuclei of cells. Phalloidine is a kind of cyclic peptides yielded by Amanita phalloides. It can combine with filamentousactin protein and often be used to stain the actin cytoskeleton of cells.

Figure 8 shows the morphology of cells with blue DAPI stain for nucleiand red phalloidine stain for actin. After $24 \mathrm{~h}$ of culture, cell proliferation was observed on both the chitosan film and GO-chitosan film, and the morphology of these cells showed no obvious variances between them (Figure 8a and b). Figure $8 \mathrm{c}$ shows the cells adhering onto the GO-chitosan film under $5 \times$ objective. Figure $8 \mathrm{~d}$ shows the cells adhering on the chitosan film under $5 \times$ objective. Figure $8 \mathrm{e}$ and $\mathrm{f}$ are higher zoom of Figure $8 \mathrm{c}$ and d, respectively. Based on cell fluorescence, GO-chitosan film is as good as chitosan film for cells adhesion. The proliferation of cells on two samples indicated that both of them had very little cytotoxicity and could have a potential for stimulating interaction between cells and the films, which could serve as an ideal platforms for cell adhesion and proliferation.

A cell viability stain was also used to test the biocompatibility of the films. The assays kit produced an intense uniform green fluorescence in live cells, while a bright red fluorescence in dead cells was observed. After $24 \mathrm{~h}$, cells on the surface of GO-chitosan film showed better viability as observed by green fluorescent staining (Figure 8g). There were large amount of dead cells with red fluorescence on the chitosan film (Figure 8h). The results indicate that the GO-chitosan film is suitable for cell proliferation.

Magrez et al. [35] explored the influence of surface functionalities on the toxicity of carbon-based 

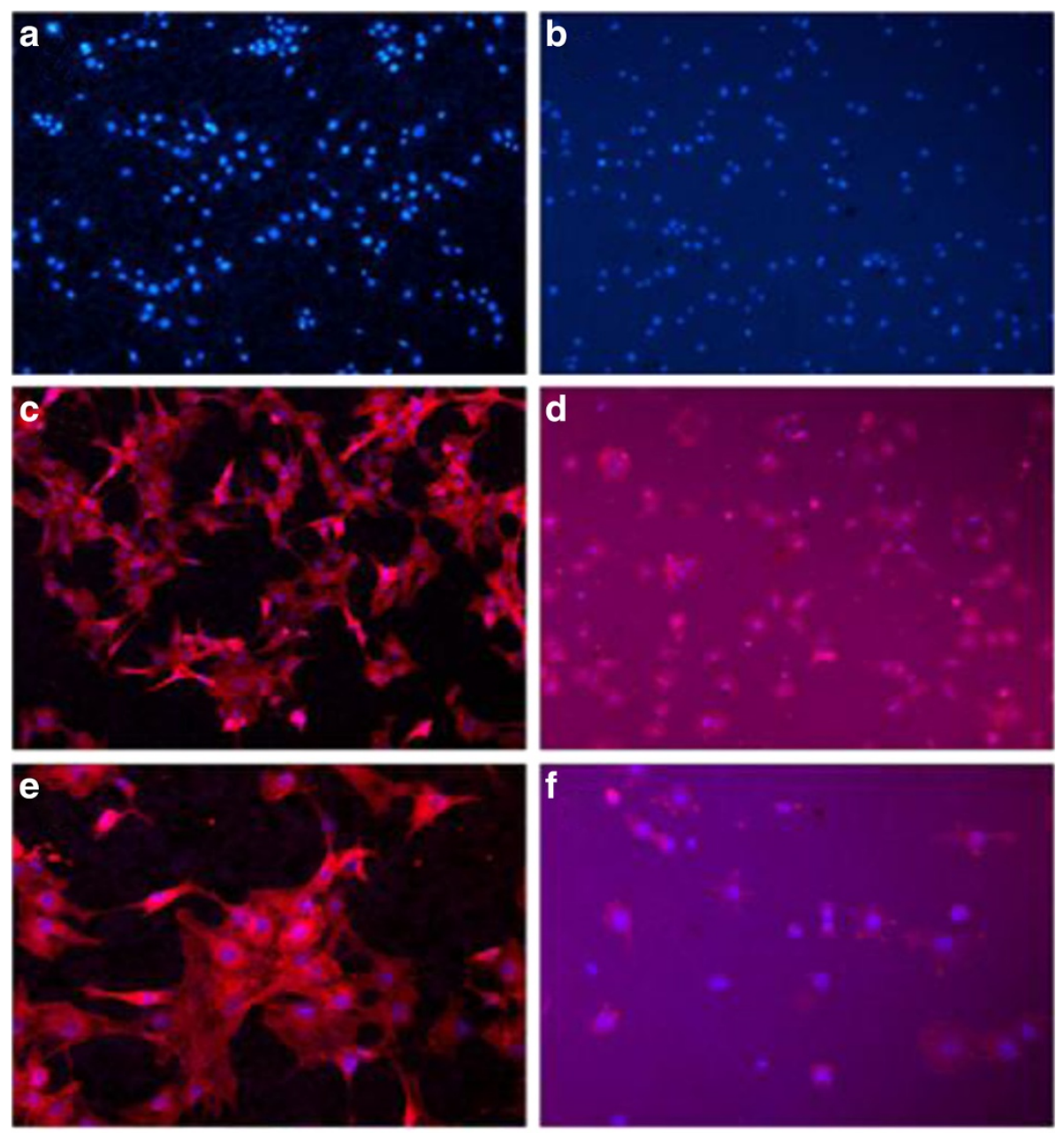

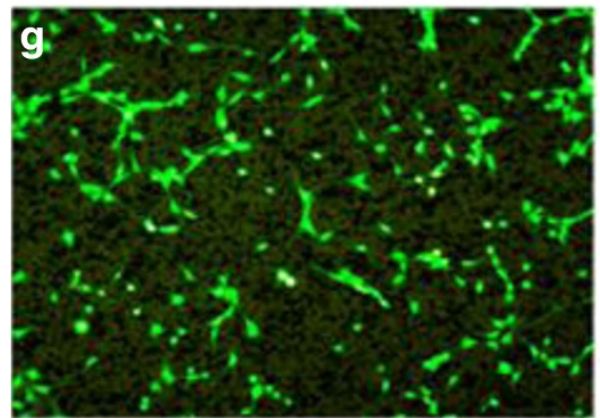

GO-chitosan

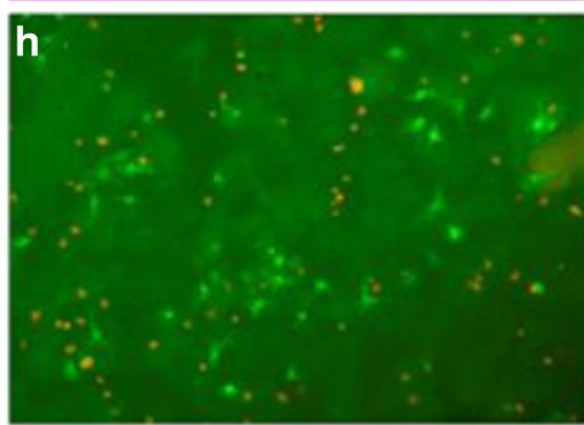

\section{chitosan}

Figure 8 Cell contrast fluorescence micrographs on GO-chitosan film and chitosan film. Cell phase contrast micrographs onGO-chitosan film (a) and on chitosan film (b) at $24 \mathrm{~h}$. (c) shows the cells adhering on the GO-chitosan film at 24 hunder 5Xobjective. (d) shows the cells adhering on the chitosan film at 24 hunder $5 X$ objective. (e) and (f) are higher zoom of (c) and (d), respectively. In the above morphology of cells, the actin stains with phalloidinin red fluorescence, while nuclei stains with DAPI in blue fluorescence. A cell viability stain on GO-chitosan film (g) and on the chitosan film (h), respectively. The assays kit produces a green fluorescence in live cells while a bright red fluorescence in dead cells.

nanomaterials (CBNs) and found out that the toxicity increased as the oxygen containing groups were introduced onto the surface of CBNs. Thus, it is intriguing to know the toxicity of GO-chitosan film with the $\mathrm{C}=\mathrm{O}, \mathrm{OH}$, and $\mathrm{COOH}$ groups on the surfaces.
However, in comparison with CBNs [36-39], these hydrophilic groups increase the solubility and dispersion of GO-chitosan, and may have limitedly negative effects on cells after chitosan is decomposed in the body. Hence, GO-chitosan film has an acceptable 
biocompatibility in a limited GO content range, providing an alternative in functional biomaterial.

\section{Conclusions}

The present study describes a useful and simple method to chemically attach biocompatible chitosan onto graphene oxide through the formation of amide linkages between GO's carboxylic acid groups and chitosan's amine groups. GO-chitosan composite films were also characterized by element analysis, Fourier transform infrared spectroscopy, X-ray photo electron spectroscopy, differential scanning calorimetry, and thermo gravimetric analysis. Both the tensile strength and Young's modulus of GO-chitosan film increase dramatically. GO-chitosan is more thermally stable than chitosan. Meanwhile, GO-chitosan film has good biocompatibility, biodegradability, and good solubility in aqueous medium, similarly to chitosan. The results of both cell proliferation and cell viability experiments indicate that GO-chitosan film is suitable for cell proliferation. Taken together, we envision that the GO-chitosan film will open avenues for next-generation graphene applications in the realm of functional biomaterial.

\section{Methods \\ Materials}

Chitosan (reagent grade) was supplied by Shanghai Weikang Biological Co. (China) with a degree of deacetylation of $93 \%$ and average molecular weight of $400,000 \mathrm{~g} / \mathrm{mol}$. Graphite powder was purchased from Shanghai Yi Fan Co., China. Sulphuric acid $\left(\mathrm{H}_{2} \mathrm{SO}_{4}\right.$, 98.0\%), potassium permanganate $\left(\mathrm{KMnO}_{4}, 99.9 \%\right)$, hydrogen peroxide $\left(\mathrm{H}_{2} \mathrm{O}_{2}, 30.0 \%\right)$, Phosphate standard concentrate $\left(\mathrm{H}_{3} \mathrm{PO}_{4}, 85.0 \%\right)$, Hydrochloric acid $(\mathrm{HCl}$, $37.0 \%)$ and acetic acid (99.9\%) were purchased from Shanghai Lingfeng Chemical Reagent Co.,China. N, $\mathrm{N}$-dimethylformamide (DMF, 99.8\% SuperDry, with molecular sieves)was purchased from J\&K Chemical (Beijing) Ltd.,China. $N, N^{\prime}$-dicyclohexylcarbodiimide (DCC, 99.0\%), 1,2-dichlorobenzene (ODCB, 99.0\%) and 4dimethylaminopyridine (DMAP,99.0\%) were purchased from Aladdin Reagent (Shanghai) Co., Ltd, China. The reagents were used without further purification.C3H10T1/2 cells were provided by the Chinese Academy of Sciences (Shanghai, China). Dulbecco's minimum essential medium (DMEM) and Penicillin and streptomycin were purchased from Thermo (USA). TritonX-100 solution, phalloidine and 4',6-diamidino2-phenylindole (DAPI)were purchased from Sigma (USA). LIVE/DEAD viability/cytotoxicity Assay Kit and Fetal Bovine Serum were purchased from Life Technologies (USA).

\section{Synthesis of graphene oxide-chitosan (GO-chitosan)} Graphene oxide (GO) was prepared according to Hummers'method [40]. Briefly, $20 \mathrm{~mL} \mathrm{H}_{3} \mathrm{PO}_{4}$ (85.0\%) and $180 \mathrm{~mL}$ of concentrated $\mathrm{H}_{2} \mathrm{SO}_{4}$ were poured into the three-neck flask charged with $1 \mathrm{~g}$ graphite powder under stirring. $6 \mathrm{~g} \mathrm{KMnO}_{4}$ was gradually added into the reaction mixture that was cooled by an ice bath. The cooling bath was removed and the reaction mixture was kept at $45^{\circ} \mathrm{C}$ for $48 \mathrm{~h}$ to ensure complete oxidation of graphite. The reaction mixture was quenched by $1 \mathrm{~L}$ of ice containing $10 \mathrm{~mL}$ of $30 \% \mathrm{H}_{2} \mathrm{O}_{2}$. The color of the mixture changed from dark brown to bright yellow, indicating formation of GO. The solid was obtained by centrifugal separation and washed 3 times with $10 \% \mathrm{HCl}$ aqueous solution followed by deionized water until $\mathrm{pH}$ of 5-6 was achieved. Finally, the resulting GO was washed with acetone and then dried at $60^{\circ} \mathrm{C}$ under vacuum for $30 \mathrm{~h}$.

Graphene oxide-chitosan composites were prepared as follows: $50 \mathrm{mg}$ GO and 1gchitosan were loaded into a $100 \mathrm{~mL}$ round-bottom flask charged with $50 \mathrm{~mL}$ DMF. The mixture was sonicated for $1 \mathrm{~h}, 0.45 \mathrm{~g}$ DCC and $0.3 \mathrm{~g}$ DMAP were then added to the above suspension and incubated for $48 \mathrm{~h}$ at room temperature. The resulting solid was isolated by centrifugation and washed with ODCB $(3 \times 50 \mathrm{~mL})$ to remove unreacted chitosan. The mixture was subsequently washed thoroughly with water $(50 \mathrm{~mL})$, methanol $(50 \mathrm{~mL})$ and acetone $(50 \mathrm{~mL})$, sequentially. Finally, it was dried at $60^{\circ} \mathrm{C}$ for $24 \mathrm{~h}$ under vacuum. The fabrication process is outlined in Scheme 1.

\section{Fabrication of chitosan film}

$500 \mathrm{mg}$ chitosan powders were dissolved in $25 \mathrm{~mL} 2 \%$ $(\mathrm{v} / \mathrm{v})$ acetic acid aqueous solution upon stirring at 200rpm for $3 \mathrm{~h}$. After that, the chitosan suspension was poured into a plastic dish that was placed in a fume hood at room temperature to evaporate water and acetic acid. The as-prepared composite film was dried under vacuum at $40^{\circ} \mathrm{C}$ until their weight was equilibrated.

\section{Fabrication of graphene oxide-chitosan (GO-chitosan) film} $500 \mathrm{mg}$ graphene oxide-chitosan powders were dissolved in $25 \mathrm{~mL} 2 \%(\mathrm{v} / \mathrm{v})$ acetic acid aqueous solution by ultrasonication for $30 \mathrm{~min}$. The homogeneous solution was then cast onto a teflon plate, left to dry at room temperature and subsequently peeled off as a free-standing film. The film was dried under vacuum at $40^{\circ} \mathrm{C}$ until its weight was equilibrated.

\section{Fabrication of graphene oxide/chitosanmix (GO/ chitosanmix) film}

$0.25 \mathrm{wt} \% \mathrm{GO}$ solution was prepared by dissolving $100 \mathrm{mg}$ $\mathrm{GO}$ in $40 \mathrm{~g}$ water and treated with ultrasonication for $30 \mathrm{~min}$. Specific amounts of chitosan powders were then 


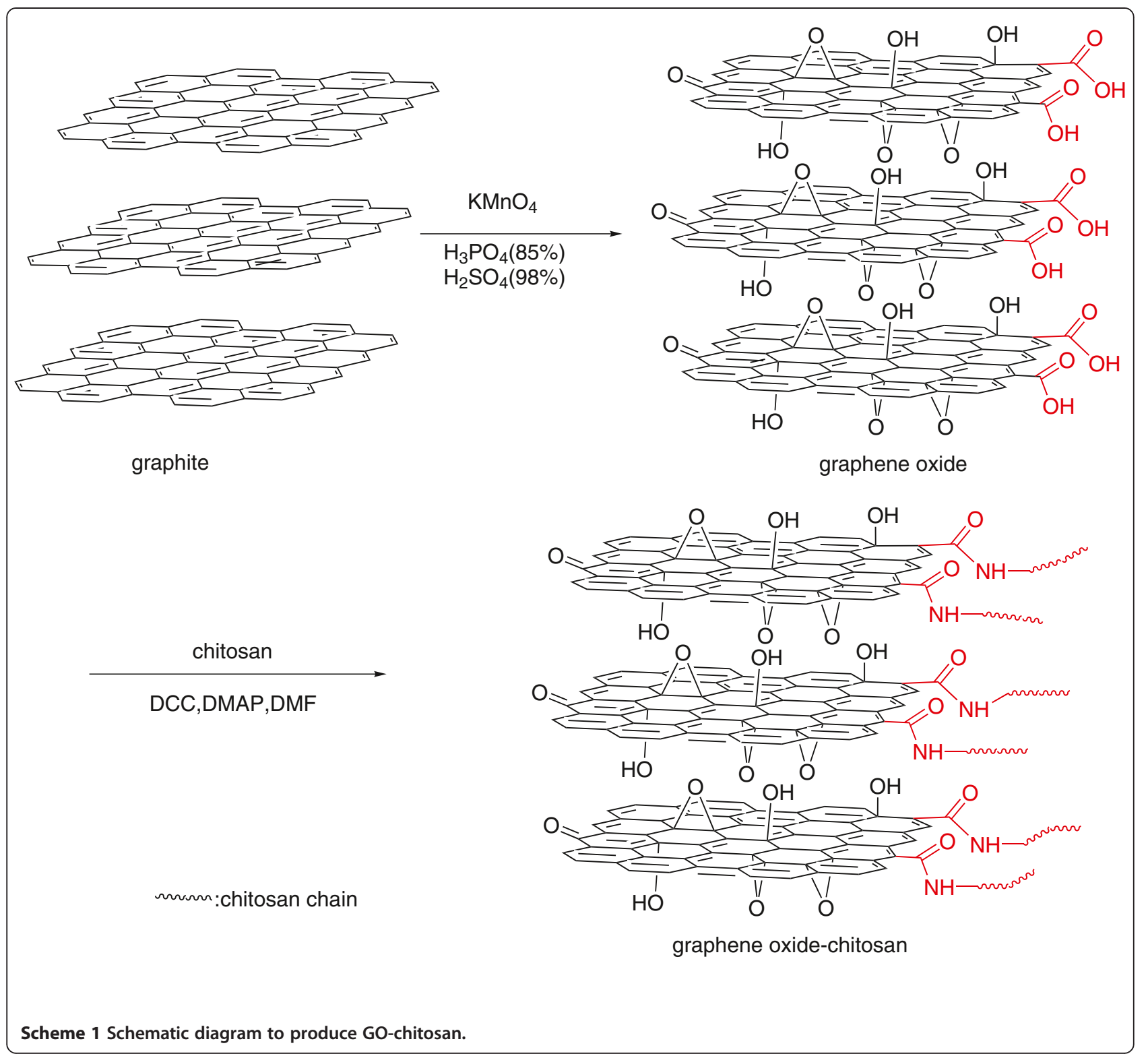

added into the GO solution, followed by ultrasound for $1 \mathrm{~h}$. The solution was then stirred at $200 \mathrm{rpm}$ for $3 \mathrm{~h}$. After stirring, the $\mathrm{GO} /$ chitosan suspension was poured into a flat dish, placed in fume hood at room temperature, allowing water to evaporate for film formation. Then, the film was stored under vacuum at $40^{\circ} \mathrm{C}$ until its weight equilibrated.

Overall, the volume of each casting solution was controlled to be $18.2 \mathrm{~mL}$. The size of all the flat dishes for film formation was $87 \mathrm{~mm} \times 87 \mathrm{~mm}$ in order that all the films were in the same size. The films were taken at random and each film was cut into 6 small pieces of $25 \mathrm{~mm} \times 25 \mathrm{~mm}$ in size. The average mass of each small piece of chitosan film, GO-chitosan film and GO/chitosan mix film was $0.128 \mathrm{~g}, 0.137 \mathrm{~g}$ and $0.132 \mathrm{~g}$, respectively.
The standard deviation of each kind of film was $4.86 \times 10^{-3}$, $4.14 \times 10^{-3}$ and $4.02 \times 10^{-3}$, correspondingly, which proved that the solution-casting method was feasible and the composite films were uniform.

\section{Characterizations}

Element analysis was carried out on Elementar Vario EL III (Germany). Fourier-transform infrared spectra (FTIR) were recorded on a Nicolet FTIR Infrared Microscopy. X-ray photoelectron spectroscopy (XPS) measurements were performed using a PHI Quantera XPS with a monochromated $\mathrm{Al} \mathrm{K} \alpha$ radiation $(\mathrm{h} v=1486.6 \mathrm{eV})$. Thermal properties of the films were studied by thermal gravimetric analysis (TGA) and differential scanning calorimetry (DSC). TGA was performed 
under a nitrogen flow $(60 \mathrm{~mL} / \mathrm{min})$, and the weight was recorded as a function of temperature. DSC was measured by a TA 2910 (USA) at heating rate $20^{\circ} \mathrm{C} / \mathrm{min}$ under $\mathrm{N}_{2}$ at a flow rate of $80 \mathrm{~mL} / \mathrm{min}$. Scanning electron microscopy (SEM)images were taken on a FEI Quanta 400 ESEM FEG. The mechanical characterization was performed on a mechanical analyser (ZWICK ZO 20/TN2S, Germany). Each film was cut into five dumbbell strips with a size of $75 \mathrm{~mm} \times 4 \mathrm{~mm}$. The lower grip was fixed and the upper grip rose at an extension rate of $10 \mathrm{~mm} / \mathrm{min}$ with a preload of $1.0 \mathrm{~N}$. All the failures occurred at the middle region of the testing strips.

\section{Biocompatibility of graphene oxide-chitosan (GO- chitosan) film \\ Cell culturing}

Mouse mesenchymal Stem C3H10T1/2 cells were cultured in Dulbecco's minimum essential medium (DMEM) supplemented with $10 \%$ Fetal Bovine Serum and a combination of $100 \mathrm{ug} / \mathrm{mL}$ penicillin and $100 \mathrm{ug} / \mathrm{mL}$ streptomycin. All incubations were at $37^{\circ} \mathrm{C}$ with a concentration of $5 \% \mathrm{CO}_{2}$.

\section{Proliferation and viability of $\mathrm{C} 3 \mathrm{H} 10 \mathrm{~T} 1 / 2$ cells}

Fluorescent staining method was used in analyzing the proliferation of cells on the surface of GO-chitosan films and chitosan films. Firstly, GO-chitosan films and chitosan films were sterilized with cyclohexane, followed by immersion in DMEM seeded with a concentration of $5 \times 10^{6}$ cells $/ \mathrm{mL}$ at $37^{\circ} \mathrm{C}$. Briefly, after being cultured for $24 \mathrm{~h}$, the samples were gently washed with phosphatebuffered saline (PBS) and maintained in $4 \%$ paraformaldehyde for $15 \mathrm{~min}$. This step was followed by being immersed in $0.1 \%$ TritonX-100 solution for $15 \mathrm{~min}$, and washed with PBS again. The samples were stained in a new 24-well plate with $500 \mu$ Lphalloidine for $1 \mathrm{~h}$, and then stained with 4,6-diamidino-2phenylindole (DAPI) for 15 min.C3H10T1/2 cells seeding on films and staining was done according to the manufacturer's instruction. Stained cells were then ready for observation through fluorescence microscope (Leica DM4000B, Germany).

A LIVE/DEAD viability/cytotoxicity Assay Kit was also used to investigate the viability of cells. Samples were prepared as described above. After C3H10T1/2 cells were cultured on the surface of GO-chitosan films and chitosan films for $24 \mathrm{~h}$, the samples were gently washed three times with PBS, and then stained in another new 24-well plate with $500 \mu \mathrm{L}$ stain solution for $45 \mathrm{~min}$. The viability of cells was observed using fluorescence microscope.

\section{Abbreviations}

GO: Graphene oxide; DMF: N,N-dimethylformamide; DCC: N,N'-

dicyclohexylcarbodiimide; DMAP: 4-dimethylaminopyridine; ODCB: 1,2- dichlorobenzene; DMEM: Dulbecco's minimum essential medium; PBS: Phosphatebuffered saline; DAPI: 4',6-diamidino-2-phenylindole; FTIR: Fourier-transform infrared spectra; XPS: X-ray photoelectron spectroscopy; TGA: Thermal gravimetric analysis; DSC: Differential scanning calorimetry; Tg: Glass transition temperature; SEM: Scanning electron microscopy.

\section{Competing interests}

The authors declare that they have no competing interests.

\section{Authors' contributions}

PPZ carried out the experiment and prepared the manuscript for submission. HFF participated in the study of biocompatibility of graphene oxide-chitosan film. ZZX participated in solving the problems in synthesizing. LFZ conducted the spectroscopic analysis. YLZ participated in the results discussion. WX interpreted the spectral data and revised the manuscript. WQZ proposed the research idea and coordinated final formulation. All authors read and approved the final manuscript.

\section{Authors' information}

Shanghai Key Laboratory of Functional Materials Chemistry, School of Chemistry and Molecular Engineering, East China University of Science and Technology, 130 Meilong Road, Shanghai, China 200237.

\section{Acknowledgements}

This work was supported by National Key Technologies R\&D Program of China (Grant 2010BAK67B15).

Received: 17 December 2012 Accepted: 7 February 2013 Published: 25 February 2013

\section{References}

1. Novoselov KS, Jiang Z, Zhang Y, Morozov SV, Stormer HL, Zeitler U, Maan JC, Boebinger GS, Kim P, Geim AK: Room-temperature quantum hall effect in graphene. Science 2007, 315:1379-1379.

2. Castro EV, Novoselov KS, Morozov SV, Peres NMR, dos Santos JMBL, Nilsson J, Guinea F, Geim AK, Neto AHC: Biased bilayer graphene: semiconductor with a Gap tunable by the electric field effect. Phys Rev Lett 2007, 99:216802.

3. Rao CNR, Sood AK, Subrahmanyam KS, Govindaraj A: Graphene: the New Two-dimensional nanomaterial. Angew Chem Int Ed 2009, 48:7752-7777.

4. Eda G, Chhowalla M: Graphene-based composite thin films for electronics. Nano Lett 2009, 9:814-818.

5. Ramanathan T, Abdala AA, Stankovich S, Dikin DA, Herrera-Alonso M, Piner RD, Adamson DH, Schniepp HC, Chen X, Ruoff RS, Nguyen ST, Aksay IA, Prud'Homme RK, Brinson LC: Functionalized graphene sheets for polymer nanocomposites. Nature Nanotech 2008, 3:327-331.

6. Si YC, Samulski ET: Synthesis of water soluble graphene. Nano Lett 2008, 8:1679-1682.

7. Li D, Muller MB, Gilje S, Kaner RB, Wallace GG: Processable aqueous dispersions of graphene nanosheets[abstract]. Nature Nanotech 2008, 3:101-105.

8. Stankovich S, Piner RD, Nguyen ST, Ruoff RS: Synthesis and exfoliation of isocyanate-treated graphene oxide nanoplatelets. Carbon 2006, 44:3342-3347

9. Bao HQ, Pan YZ, Ping Y, Sahoo NG, Wu TF, Li L, Li J, Gan LH: Chitosanfunctionalized graphene oxide as a nanocarrier for drug and gene delivery. Small 2011, 7:1569-1578.

10. Hu FX, Chen SH, Wang CY, Yuan R, Yuan DH, Wang C: Study on the application of reduced graphene oxide and multiwall carbon nanotubes hybrid materials for simultaneous determination of catechol, hydroquinone, p-cresol and nitrite. Anal Chim Acta 2012, 724:40-46.

11. $\mathrm{Hu} X \mathrm{XG}, \mathrm{Mu} \mathrm{L}$, Wen JP, Zhou QX: Covalently synthesized graphene oxideaptamernanosheets for efficient visible-light photocatalysis of nucleic acids and proteins of viruses. Carbon 2012, 50:2772-2781.

12. Shen JF, Yan B, Shi M, Ma HW, Li N, Ye MX: Synthesis of graphene oxidebased biocomposites through diimide-activated amidation. J Colloid Interface Sci 2011, 356:543-549.

13. Sun XM, Liu Z, Welsher K, Robinson JT, Goodwin A, Zaric S, Dai HJ: Nanographene oxide for cellular imaging and drug delivery. Nano Res 2008, 1:203-212. 
14. Liu Z, Robinson JT, Sun XM, Dai HJ: PEGylatedNanographene oxide for delivery of water-insoluble cancer drugs. J Am Chem Soc 2008, 130:10876-10877.

15. Rinaudo M: Chitin and chitosan: Properties and applications. Prog Polym Sci 2006, 31:603-632.

16. Francis Suh JK, Matthew HWT: Application of chitosan-based polysaccharide biomaterials in cartilage tissue engineering: a review. Biomaterials 2000, 21:2589-2598.

17. Han DL, Yan LF, Chen WF, Li W: Preparation of chitosan/graphene oxide composite film with enhanced mechanical strength in the wet state. Carbohydr Polym 2011, 83:653-658.

18. Fan HL, Wang LL, Zhao KK, Li N, Shi ZJ, Ge ZG, Jin ZX: Fabrication, mechanical properties, and biocompatibility of graphene-reinforced chitosan composites. Biomacromolecules 2010, 11:2345-2351.

19. Pan $Y Z, W u T F$, Bao $H Q$, Li L: Green fabrication of chitosan films reinforced with parallel aligned graphene oxide. Carbohydr Polym 2011, 83:1908-1915.

20. Yang XM, Tu YF, Li L, Shang SM, Tao XM: Well-dispersed chitosan/ graphene oxide nanocomposites. ACS Appl Mater Interfaces 2010, 2:1707-1713.

21. Brugnerotto J, Lizardi J, Goycoolea FM, Argüelles-Monal W, Desbrières J, Rinaudo M: An infrared investigation in relation with chitin and chitosan characterization. Polymer 2001, 42:3569-3580

22. Ravi Kumar MNV: A review of chitin and chitosan applications. React Funct Polym 2000, 46:1-27.

23. Datta P, Dhara S, Chatterjee J: Hydrogels and electrospunnanofibrous scaffolds of $\mathrm{N}$-methylene phosphonic chitosan as bioinspiredosteoconductive materials for bone grafting. Carbohydr Polym 2012, 87:1354-1362

24. Meng S, Zhang Z, Rouabhia M: Accelerated osteoblast mineralization on a conductive substrate by multiple electrical stimulation. J Bone Miner Metab 2011, 29:535-544.

25. Marcano DC, Kosynkin DV, Berlin JM, Sinitskii A, Sun ZZ, Slesarev A, Alemany LB, Lu W, Tour JM: Improved synthesis of graphene oxide. ACS Nano 2010, 4:4806-4814.

26. Lee WC, Lim CHYX, Shi H, Tang LAL, Wang Y, Lim CT, Loh KP: Origin of enhanced stem cell growth and differentiation on graphene and graphene oxide. ACS Nano 2011, 5:7334-7341.

27. Compton OC, Dikin DA, Putz KW, Brinson LC, Nguyen ST: Electrically conductive "alkylated" graphene paper via chemical reduction of aminefunctionalized graphene oxide paper. Adv Mater 2010, 22:892-896.

28. Yang YF, Wang J, Zhang J, Liu JC, Yang XL, Zhao HY: Exfoliated graphite oxide decorated by PDMAEMA chains and polymer particles. Langmuir 2009, 25:11808-11814.

29. Stankovich S, Dikin DA, Piner RD, Kohlhaas KA, Kleinhammes A, Jia YY, Wu Y Nguyen ST, Ruoff RS: Synthesis of graphene-based nanosheets via chemical reduction of exfoliated graphite oxide. Carbon 2007, 45:1558-1565

30. Vadukumpully S, Paul J, Mahanta N, Valiyaveettil S: Flexible conductive graphene/poly (vinyl chloride) composite thin films with high mechanical strength and thermal stability. Carbon 2011, 49:198-205.

31. Zhou XS, Wu TB, Hu BJ, Yang GY, Han BX: Synthesis of graphene/ polyaniline composite nanosheets mediated by polymerized ionic liquid. Chem Commun 2010, 46:3663-3665

32. Shen JF, Hu YZ, Li C, Qin C, Ye MX: Synthesis of amphiphilic graphene nanoplatelets. Small 2009, 5:82-85.

33. Zhao X, Zhang QH, Chen DJ, Lu P: Enhanced mechanical properties of graphene-based poly (vinyl alcohol) composites. Macromolecules 2010 43:2357-2363.

34. Lim HN, Huang NM, Loo CH: Facile preparation of graphene-based chitosan films: Enhanced thermal, mechanical and antibacterial properties. J Non-Cryst Solids 2012, 358:525-530.

35. Magrez A, Kasas S, Salicio V, Pasquier N, Seo JW, Celio M, Catsicas S, Schwaller B, Forró L: Cellular toxicity of carbon-based nanomaterials. Nano Lett 2006, 6:1121-1125.

36. Isobe H, Tanaka T, Maeda R, Noiri E, Solin N, Yudasaka M, lijima S, Nakamura E: Preparation, purification, characterization, and cytotoxicity assessment of water-soluble, transition-metal-free carbon nanotube aggregates. Angew Chem Int Ed 2006, 40:6828-6832.

37. Smart SK, Cassady Al, Lu GQ, Martin DJ: The biocompatibility of carbon nanotubes. Carbon 2006, 44:1034-1047.
38. Liao KH, Lin YS, Macosko CW, Haynes CL: Cytotoxicity of graphene oxide and graphene in human erythrocytes and skin fibroblasts. ACS Appl Mater Interfaces 2011, 3:2607-2615.

39. Yang K, Li YJ, Tan XF, Peng R, Liu Z: Behavior and toxicity of graphene and its functionalized derivatives in biological systems. Small 2012. early view online.

40. Hummers WS, Offeman RE: Preparation of graphitic oxide. J Am Chem Soc 1958, 80:1339-1339.

doi:10.1186/1752-153X-7-39

Cite this article as: Zuo et al:: Fabrication of biocompatible and mechanically reinforced graphene oxide-chitosan nanocomposite films.

Chemistry Central Journal 2013 7:39.

\section{Publish with ChemistryCentral and every scientist can read your work free of charge \\ "Open access provides opportunities to our colleagues in other parts of the globe, by allowing anyone to view the content free of charge." \\ W. Jeffery Hurst, The Hershey Company.}

- available free of charge to the entire scientific community

- peer reviewed and published immediately upon acceptance

- cited in PubMed and archived on PubMed Central

- yours - you keep the copyright

Submit your manuscript here:

http://www.chemistrycentral.com/manuscript/
()

ChemistryCentral 